\title{
Epidermal growth factor receptor and proliferating cell nuclear antigen in astrocytomas
}

\author{
Arpan K. Maiti, Keya Ghosh ${ }^{1}$, Uttara Chatterjee ${ }^{1}$, Sasanka Chakrobarti, Sandip Chatterjee ${ }^{2}$, \\ Samik Basu ${ }^{3}$ \\ Departments of Biochemistry and ${ }^{1}$ Pathology, Institute of Post Graduate Medical Education and Research, 244, A J C Bose Road, ${ }^{2}$ Park Clinic, \\ 4 Gorky Terrace, ${ }^{3}$ Bhagirathi Neotia Women and Child Care Centre, 2 Rawdon Street, Kolkata, India
}

\begin{abstract}
Aims: The involvement of various growth factors, growth factor receptors and proliferative markers in the molecular pathogenesis of astrocytic neoplasms are being studied extensively. Epidermal Growth Factor Receptor (EGFR) gene overexpression occurs in nearly $50 \%$ of cases of glioblastoma. Since EGFR and proliferating cell nuclear antigen (PCNA) are involved in mitogenic signal transduction and cellular proliferation pathway, we have studied the correlation between the expression of EGFR and PCNA labeling index in astrocytic tumors. Materials and Methods: We investigated the immunohistochemical expression of EGFR and PCNA using the appropriate monoclonal antibodies in 40 cases of astrocytic tumors of which 21 cases were glioblastoma, eight cases were Grade III or anaplastic astrocytomas and six cases were Grade II or diffuse astrocytomas and five cases were Grade I or pilocytic astrocytomas. Results: Both the EGFR expression and PCNA labeling index increase with increasing grades of astrocytomas with a significantly high percentage of cells showing positive staining for both EGFR and PCNA in GBM and Grade III astrocytomas compared to Grade II astrocytomas. The expression levels of both EGFR and PCNA were low in Grade I or pilocytic astrocytomas. Conclusions: A significant correlation was found between EGFR overexpression and PCNA labeling index in Grade III and Grade II astrocytomas and glioblastoma. These suggest that the tumor proliferation, at least in higher grades of astrocytomas is dependent in some measure on EGF and EGFR-related signaling pathways.
\end{abstract}

Key words: Astrocytoma, epidermal growth factor receptor, glioblastoma, proliferating cell nuclear antigen

\section{Introduction}

Astrocytic tumors comprise a wide range of neoplasms that differ in their location within the Central Nervous System (CNS), age and gender distribution, growth potential, extent of invasiveness, morphological features, tendency for progression and clinical course. These differences may reflect the type and sequence of genetic alterations acquired during the process of transformation..$^{[1-5]}$

The histological grade continues to be one of the most important prognostic indicators but the roles of various newer prognostic factors are being investigated. These include various growth factors like Epidermal Growth factor (EGF), Platelet Derived growth factor (PDGF), Vascular Endothelial Growth Factor (VEGF), growth factor receptors like EGFR, Platelet Derived growth factor receptor (PDGFR), mutations of various oncogenes or tumor-suppressor genes, cytogenetic abnormalities and parameters of angiogenesis. Role of various proliferative markers like, PCNA, Ki67 (MIB-1), BudR labeling index, AgNOR, are also increasingly being investigated with increasing grades of astrocytomas. There is increasing evidence that the progression from low-grade to anaplastic astrocytoma and glioblastoma multiforme (GBM) is associated with cumulative acquisition of multiple genetic alterations involving proto-oncogenes and tumor suppressor genes. $^{[6-9]}$ The most frequently amplified growth factor receptor gene in astrocytic tumors is the EGFR gene present on Chromosome 7, which shares a structural homology with v-erbB oncogene. ${ }^{[6,7]}$

Epidermal growth factor has been suggested as a mitogenic hormone which may be involved in the regulation of proliferation and differentiation of normal and neoplastic cells. The EGFR is a transmembrane glycoprotein and binding of EGF or TGF- $\alpha$ to this receptor results in an intracellular response leading to mitosis by activation of the tyrosine kinase. EGFRs are 


\begin{tabular}{|c|c|c|}
\hline \multicolumn{3}{|c|}{ Table 1: Comparison between primary and secondary glioblastomas } \\
\hline & Primary glioblastoma & Secondary glioblastoma \\
\hline Age & Older people are affected (Mean age 55 years) & Young adults are affected (30-45 years) \\
\hline Clinical history & Short ( $<6$ months $)$ & Long ( $4-5$ years) \\
\hline Histopathology & $\begin{array}{l}\text { Nuclear atypia, mitosis, endothelial proliferation, } \\
\text { necrosis }\end{array}$ & $\begin{array}{l}\text { Evidence of evolution from low-grade to high- } \\
\text { grade tumors }\end{array}$ \\
\hline \multicolumn{3}{|l|}{ Immunophenotypic criteria } \\
\hline EGFR amplification & Present & Rare \\
\hline LOH of chromosome 10 & Present & Rare \\
\hline P53 mutation & Rare & Present \\
\hline LOH on chromosome $17 p$ & Rare & Present \\
\hline
\end{tabular}

of two types -wild type and mutant type (EGFRVIII). The wild-type EGFR protein is $170 \mathrm{KDa}$ and belongs to the ErbB subfamily of tyrosine kinase receptors. EGFRmediated signaling occurs through various coupling and adaptor proteins like Shc and Grb causing enhanced tumourigenicity through both increased cellular proliferation and reduced apoptosis. ${ }^{[9-12]}$ However, the exact mechanisms of downstream signaling pathways are still being investigated. The amount of EGFR appears to vary according to the cell type and stage of differentiation of many malignant tumors. EGFR gene amplification occurs in approximately $40 \%$ of glioblastoma (GBM) cases whereas EGFR protein overexpression has been reported in a slightly higher percentage of cases. ${ }^{[9,11,13-17]}$ Torp et al. ${ }^{[10]}$ have shown that the high-grade gliomas contain more tumor cells rich in EGFR than do the low-grade gliomas, but its clinical significance is yet to be established. ${ }^{[18-23]}$

Immunoreactivity for the EGFR prevailed in $>60 \%$ cases of primary glioblastoma in contrast to $10 \%$ of cases of secondary glioblastomas are given in Table $1 .^{[24]}$

PCNA is a cofactor for DNA polymerase delta and is a substrate in RAD6 pathway causing DNA repair. DNA polymerase delta is the major enzyme for the replication of eukaryotic DNA and has a proofreading activity and is expected to play a significant role in the maintenance of the fidelity of mammalian DNA replication. PCNA is well recognized as a marker for proliferative activity in various types of neoplasm. However, while levels of PCNA are normally very low in non-cycling cells, high levels of the protein have been observed in the normal tissues surrounding human breast and pancreatic tumors. Hall et al., ${ }^{[25]}$ showed that PCNA can be induced in non-cycling cells by adjacent transplanted tumor cells and this phenomenon can be mimicked by the in vivo administration of growth factors (transforming growth factor alpha and epidermal growth factor).

PCNA expression increases in the cell during S-phase as well as during extensive DNA damage. Studies by Masih et al., ${ }^{[26]}$ suggested that PCNA may be responsible for recruitment of MMR (Mismatch Repair) machinery to actively replicating DNA. MMR is the primary postreplicative DNA repair event. Bian et al., ${ }^{[21]}$ have studied the pathologic significance of the proliferative activity and oncoprotein expression in astrocytic tumors, but their results do not show significant positive correlation with grade or prognosis of tumors. Sallien et al., ${ }^{[27]}$ found strong association of three proliferative indices like Ki-67 (MIB-1), PCNA immunoreactivity and flow cytometry for S-phase and S+G2\M phase fraction with the grade of astrocytomas (I-IV). Because PCNA is a marker of G1, S, G2 and M-phases of the cell cycle and because of its long half-life (12 h) PCNA may be detected immunohistochemically in cells that have recently left the cell cycle. ${ }^{[28]}$ Scott et al., ${ }^{[29]}$ suggested that PCNA Labelling Index indicates the relationship of PCNA Labelling Index and proliferative activity continuously.

In the present study, we have attempted to evaluate and compare the EGFR protein expression and PCNA labeling index in different grades of astrocytic neoplasms in order to elucidate the possible link between proliferative activity, oncoprotein expression and the histological grade. The relationship between EGFR protein expression and PCNA labeling index has not been previously evaluated.

\section{Materials and Methods}

A total of 40 cases were collected for a period of three years from June 2003 to May 2006. All the cases were diagnosed as primary brain tumors. Tissues were fixed in $10 \%$ formalin, processed and serial cut sections $(5 \mu \mathrm{m}$ thickness) were obtained with a microtome. The sections were stained by hematoxylin and eosin ( $\mathrm{H}$ and $\mathrm{E}$ ) to identify the nature of primary brain tumors according to WHO classification. All the slides were examined separately by two pathologists and the differences in opinion were resolved by consensus. Amongst 40 cases, 21 cases were diagnosed as glioblastoma, eight cases were anaplastic or Grade III astrocytomas, six cases were diffuse or Grade II astrocytomas and five cases were Grade I or pilocytic astrocytomas.

Consecutive serial sections were immunostained with SIGMA-ALDRICH ImmunotypeTM, Cat No. E3138 monoclonal anti-EGFR antibody (mouse IG1 isotype) clone $\mathrm{F} 4$ representing residues 985 to 996 of human EGFR to see the EGFR expression and by mouse monoclonal anti-PCNA antibody (Immunotech, Cat No. 2144) to assess the labeling index of proliferative 


\begin{tabular}{|c|c|c|c|c|c|c|c|c|}
\hline \multirow{4}{*}{ Age group (in years) } & \multirow{2}{*}{\multicolumn{8}{|c|}{ WHO grade of astrocytoma }} \\
\hline & & & & & & & & \\
\hline & \multicolumn{2}{|c|}{$I(n=5)$} & \multicolumn{2}{|c|}{ II $(n=6)$} & \multicolumn{2}{|c|}{ III $(n=8)$} & \multicolumn{2}{|c|}{ IV (n= 21) } \\
\hline & Male & Female & Male & Female & Male & Female & Male & Female \\
\hline $1-10$ & 1 & - & & - & - & - & 1 & - \\
\hline $11-20$ & - & - & 1 & - & 1 & - & - & - \\
\hline $21-30$ & 1 & - & & 1 & - & 1 & 2 & - \\
\hline $31-40$ & 1 & 1 & 2 & 2 & - & - & 2 & 1 \\
\hline $41-50$ & 1 & - & & - & 3 & - & 3 & 1 \\
\hline $51-60$ & - & - & 2 & - & 1 & - & 4 & 2 \\
\hline $61-70$ & - & - & - & - & 1 & 1 & 3 & - \\
\hline $71-80$ & - & - & - & - & - & - & 2 & - \\
\hline Total & 4 & 1 & 5 & 1 & 6 & 2 & 17 & 4 \\
\hline Male: Female & \multirow{2}{*}{\multicolumn{2}{|c|}{$\begin{array}{c}4: 1 \\
30.1\end{array}$}} & \multirow{2}{*}{\multicolumn{2}{|c|}{$\begin{array}{c}5: 1 \\
38.5\end{array}$}} & \multirow{2}{*}{\multicolumn{2}{|c|}{$\begin{array}{l}3: 1 \\
55\end{array}$}} & \multirow{2}{*}{\multicolumn{2}{|c|}{$\begin{array}{c}4.25: 1 \\
49\end{array}$}} \\
\hline mean age & & & & & & & & \\
\hline
\end{tabular}

activity. Standard immunostaining protocols using streptavidin-biotin immunoperoxidase method were utilized for both EGFR and PCNA immunostaining using monoclonal anti-EGFR and monoclonal antiPCNA antibodies on poly-L-lysine coated slides. During immunostaining of PCNA, antigen retrieval was done by "heat treatment" in pressure cooker using $10 \mathrm{mM}$ citrate buffer, $\mathrm{pH}$ 6. Protease treatment for 10 min was done prior to primary antibody treatment for EGFR. AntiEGFR antibody directed against the intracytoplasmic domain of EGFR and anti-PCNA antibody were used at concentrations of 1:100 and 1:200 respectively. The slides were incubated overnight at $4^{\circ} \mathrm{C}$ in moist chamber with primary antibody. Sections taken from placental tissue were taken as positive controls. The brown color of EGFR immunostaining was cytoplasmic, with accentuation at the cell periphery i.e. at cell membrane. Extent of EGFR immunostaining is graded as follows:

\begin{tabular}{lc}
\hline Extent of staining & Grade \\
$<10 \%$ of cells showing positive staining & Mild \\
$10-20 \%$ cells showing positive staining & Moderate \\
$>20 \%$ cells showing positive staining & Severe \\
\hline
\end{tabular}

PCNA immunostaining showed brown coloration of nuclei indicating positive staining. Unstained nuclei took blue color of hematoxylin. Normal tonsils were used as a positive control. PCNA Labeling Index (LI) was calculated as follows:

$$
\begin{aligned}
& \text { PCNA Labeling }=\frac{\begin{array}{l}
\text { Number of nuclei showing positive } \\
\text { staining (brown colour) }
\end{array}}{\text { Total number of nuclei }} \times 100 \% \\
& \text { Index }
\end{aligned}
$$

\section{Statistical analysis}

Data were analyzed for statistical significance between EGFR expression and PCNA LI within each grade of astrocytomas. The level of significance (alpha) was calculated at 0.05 for the cases and a 'p-value' less than 0.01 was considered highly significant within 95\% confidence limit. The arithmetic means, standard deviations and p-values were calculated for Grade II, Grade III and Grade IV astrocytoma cases and unpaired t-test was done for comparison. Correlation of EGFR expression and PCNA labeling index was done using Pearson correlation.

\section{Results}

We collected 40 cases of astrocytoma out of which 21 cases were of glioblastoma or Grade IV astrocytoma (52.5\%), eight cases of anaplastic astrocytoma or Grade III astrocytoma (20\%), six cases of diffuse Grade II astrocytoma (15\%) and five cases were Grade I or pilocytic astrocytoma (12.5\%). Age group and gender distribution within different grades of astrocytoma are given in Table 2.

The mean percentage of EGFR-positive cells was $2.17+/-0.475$ in Grade II astrocytoma ( $\mathrm{n}=6), 12.63$ $+/-1.79$ in Grade III astrocytoma $(\mathrm{n}=8)$ and $22.86+/-$ 1.792 in glioblastoma $(n=21)$ within $95 \%$ confidence limit [Figure 1]. There was significant increase in EGFR positivity from lower to higher grades. The extent of EGFR positivity in Grade III astrocytomas was significantly higher $(p=00036$ i.e. $p<0.05$ with degree of freedom $=1$ ) than that of Grade II astrocytomas [Figure 1]. Similarly, the extent of EGFR positivity in glioblastoma was significantly higher $(p<0.05)$ than that of Grade III astrocytomas [Figure 1]. Statistical significance was calculated by students t-test

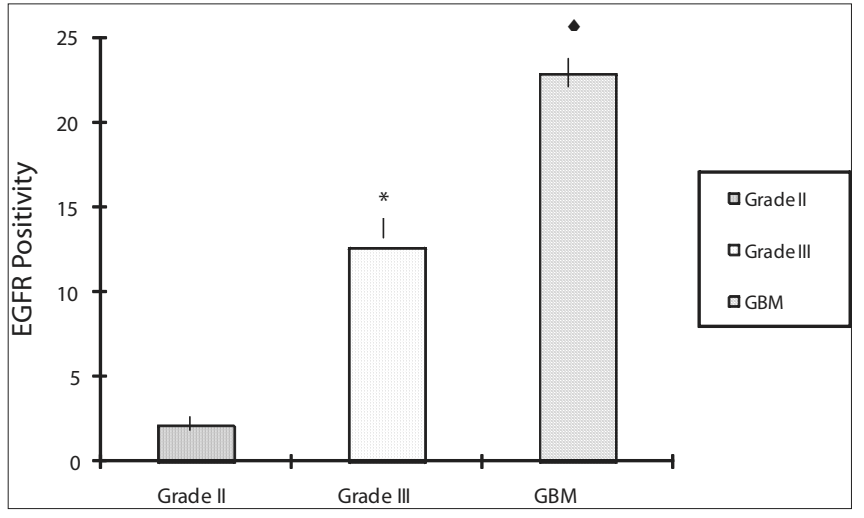

Figure 1: Comparison of epidermal growth factor receptor (EGFR) positivity in different grades of astrocytoma. The values are $2.17 \%$ in Grade II astrocytoma, $12.63 \%$ in Grade III astrocytoma and $22.86 \%$ in glioblastoma 


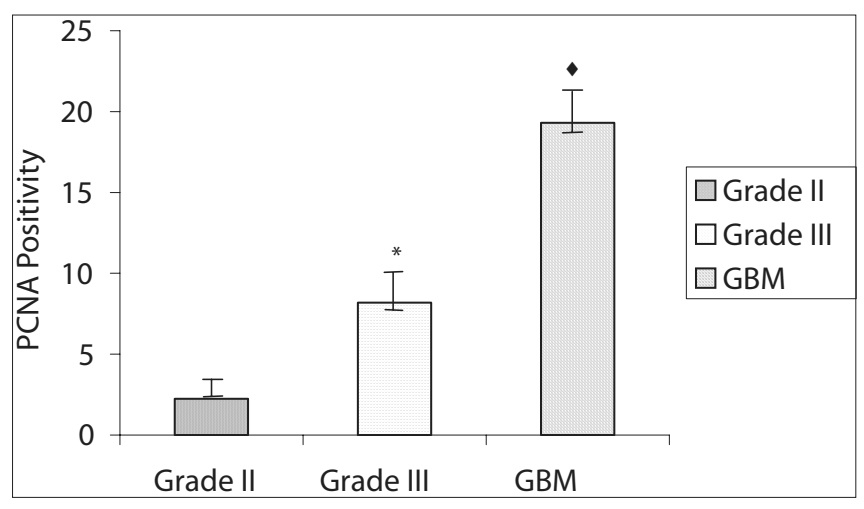

Figure 2: Comparison of proliferating cell nuclear antigen (PCNA) positivity in different grades of astrocytoma

unpaired.

The PCNA labeling indices in Grade II, III astrocytomas and glioblastoma are $2.25+/-0.214$ in Grade II astrocytoma $(\mathrm{n}=6), 8.18+/-1.78$ in Grade III astrocytoma $(\mathrm{n}=8)$ and $19.30+/-1.424$ in glioblastoma $(\mathrm{n}=21)$ within $95 \%$ confidence limit [Figure 2]. It was observed that the mean PCNA labeling index of Grade III astrocytomas was significantly higher $(p=00047$ i.e. $p<0.05$ with degree of freedom = 1) than that of Grade II astrocytomas [Figure 2]. Similar comparison between glioblastoma and Grade III astrocytomas showed that the mean PCNA labeling index of glioblastoma was significantly higher $(p=00094$ i.e. $p<0.05$ with degree of freedom =1) than that of anaplastic astrocytomas [Figure 2]. Statistical significance was calculated by student's t-test unpaired.

The values of PCNA labelling indices are $2.25 \%$ in Grade II astrocytoma, 8.18\% in Grade III astrocytoma and $19.30 \%$ in glioblastoma. Thus, significant correlation was observed between PCNA LI and increasing grades of astrocytomas, similar to the EGFR expression pattern. Grade III astrocytomas and GBM showed significant positive correlation between overexpression of EGFR and PCNA labeling index. Statistical correlation of extent of EGFR expression and PCNA labeling index was done by using Pearson correlation test. In case of glioblastomas we got Pearson correlation coefficient or $\mathrm{r}=0.36$ which indicates positive correlation between EGFR expression and PCNA labeling index in glioblastomas.

In case of Grade III astrocytomas we got the Pearson correlation coefficient or $\mathrm{r}=0.41$ which also indicates positive correlation between extent of EGFR expression and PCNA labeling index in Grade III astrocytomas.

In case of Grade II astrocytomas we got the Pearson correlation coefficient or $\mathrm{r}=0.74$ which also indicate more strong positive correlation between extent of EGFR expression and PCNA labeling index in Grade II astrocytomas.

Since the expression levels of EGFR and PCNA were low in Grade I or pilocytic astrocytomas, the correlation of these two parameters was not considered.
The photomicrographs showing EGFR immunostaining in case of GBM are presented in Figure 3A-C.

The photomicrographs showing PCNA immunostaining in case of GBM are shown in Figure-4A and B. Cases of Grade III astrocytoma showed variable immunostaining for both EGFR and PCNA (photographs not shown). Amongst the cases of Grade II astrocytoma EGFR and PCNA staining was present in only some of the cases with very low percentage of positivity (photographs not shown). The cases of Grade I, pilocytic astrocytomas did not show EGFR or PCNA immunostaining (photomicrographs not shown).

\section{Discussion}

Astrocytic tumors begin as early as in the first decade of life. Young adults are typically affected by low-grade astrocytomas while GBM shows a peak incidence in the sixth decade. Anaplastic astrocytomas occupy an intermediate position. ${ }^{[1]}$ Glioblastoma multiforme are among the most malignant human neoplasms with a mean duration of survival less than one year. Factors associated with tumor progression and affecting prognosis are still unidentified. Extensive research works on the molecular pathogenesis of GBM may facilitate molecular classification of this tumor and predict prognostic markers. Expression of EGFR is important in molecular classification and is considered as a new prognostic parameter for astrocytic tumors. ${ }^{[5,7-11]}$

The five cases of Grade I pilocytic astrocytomas showed mainly negative immunostaining both with anti-EGFR and anti-PCNA antibody, which is why we have excluded them during analysis of EGFR positivity and PCNA labeling indices. In a similar study, van der Valk et al. ${ }^{[30]}$ have also found negative EGFR immunostain in Grade I astrocytomas. However, EGFR positivity has been observed in Grade II, Grade III and Grade IV astrocytomas with increasing EGFR positivity associated with higher grades of astrocytomas. The results are in agreement with those reported by Smith et al., ${ }^{[31]}$ in a similar study. Our study further shows a mean EGFR positivity of $12.63 \%$ in anaplastic astrocytomas [Figure 1]. Torp et al..$^{[10]}$ and van der Valk et al., ${ }^{[30]}$ also have reported similar distributions of EGFR positivity within anaplastic astrocytoma cases. Although all 21 cases of GBM show high positivity for EGFR immunostain with a mean of $22.86 \%$, the extent of EGFR positivity varies from case to case. Both Torp et al. ${ }^{[10]}$ and van der Valk et al., ${ }^{[30]}$ have found similar high incidence of EGFR positivity in higher grades of human gliomas but in contrary to the above findings Waha et al. ${ }^{[32]}$ and Bouvier et al., ${ }^{[33]}$ have reported lower degrees of EGFR positivity by immunohistochemistry method. Such discrepancies may be due to heterogeneity of expression of EGFR within the tumor and use of 

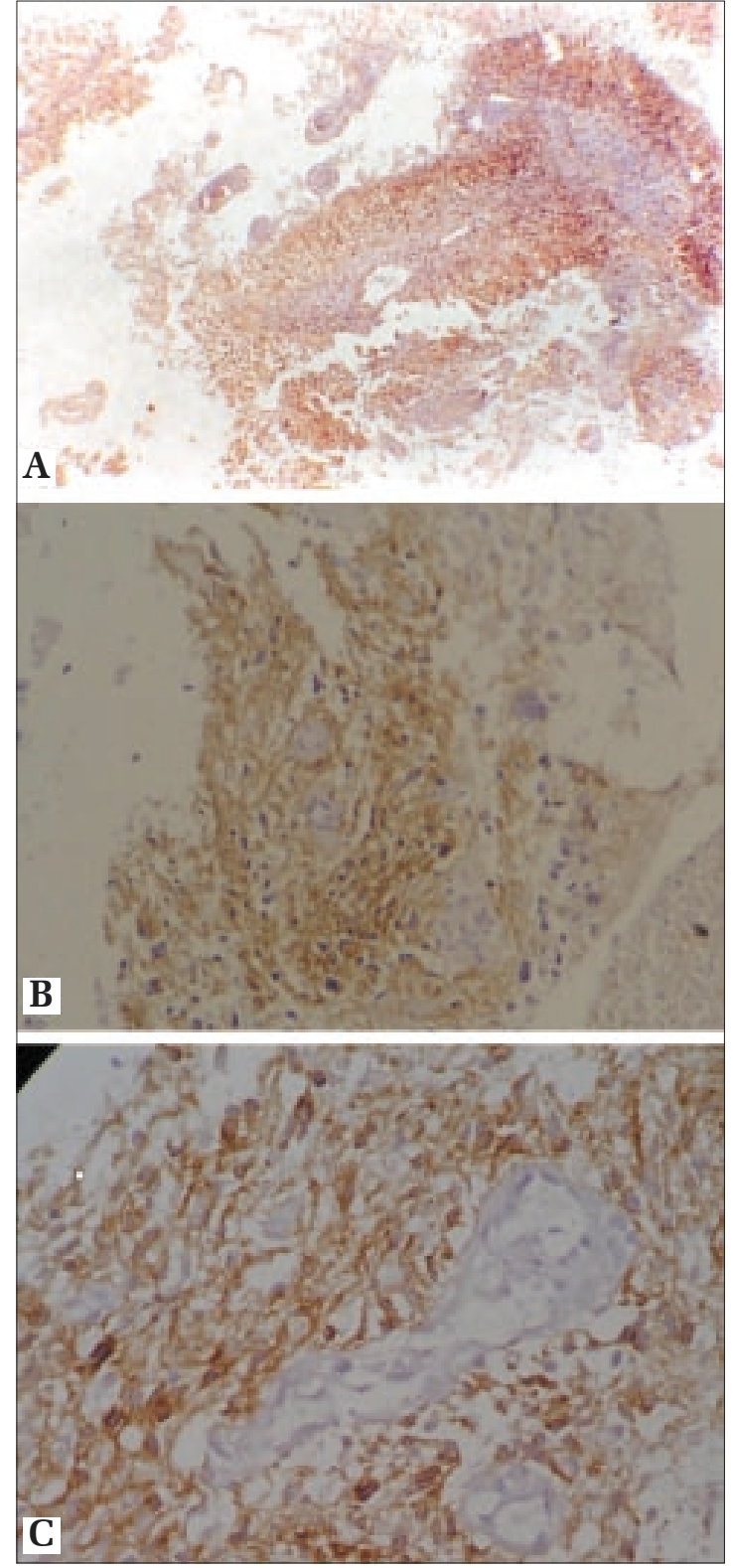

Figure 3 (A-C): Epidermal Growth Factor Receptor immunoreactivity in a case of glioblastoma

different staining protocols.

In the present study we have further determined the proliferative activity of the glioma cells by determining PCNA labeling index and found positive PCNA labeling index in Grade II (2.25\%), Grade III (8.15\%) and Grade IV (19.31\%) gliomas respectively. Yoshimura et al.. ${ }^{[34]}$ in their study have reported mean PCNA labeling index of $37 \%, 10.8 \%$ and $2.9 \%$ in cases of GBM, anaplastic astrocytomas and Grade II astrocytoma respectively. Bian et al., ${ }^{[21]}$ also found that PCNA LI amongst 97 astrocytic tumors was significantly related to Silver staining nucleolar organizer regions (AgNORs), grading and prognosis of astrocytoma. It is interesting to observe the statistically significant and positive correlation between degrees of EGFR positivity and PCNA labeling
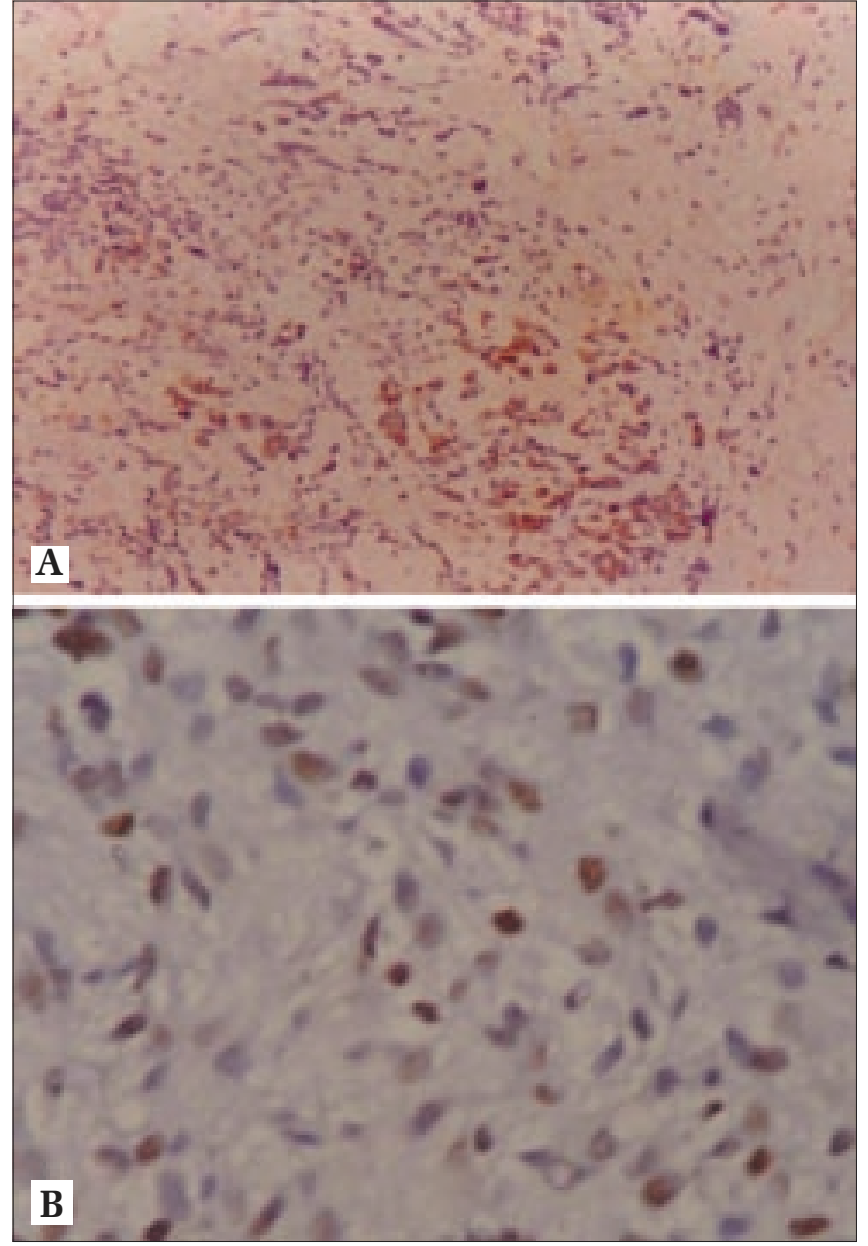

Figure 4 (A-B): Proliferating cell nuclear antigen immunoreactivity in a case of glioblastoma

index (a measure of proliferative activity) in Grade III and Grade IV glioblastomas. But presumably because of a small sample size the degree of positive correlation is statistically significant but not very strong.

The expression of EGFR is important in molecular classification of astrocytic tumors and is considered as a prognostic marker with poor prognosis associated with increased level of EGFR in anaplastic astrocytomas and glioblastomas. Although other growth factors like platelet derived growth factor (PDGF), transforming growth factor (TGF), fibroblast growth factor (FGF) and interleukin-2 produce variable stimulatory effects on glioma cell proliferation, migration and invasion, EGF appears to be much more potent in this respect. ${ }^{[13,35]}$ In vitro experiments with different glioma cell lines or tumor spherules have clearly demonstrated the involvement of EGF and EGFR in the growth and multiplication of neoplastic cells. ${ }^{[13,16,18,35]}$

In most of the earlier reports the expressions of the EGFR and other proliferative markers have been studied separately in cases of GBMs and other astrocytic neoplasms. In contrast to such studies, the present work has evaluated the levels of expression of both EGFR 
and PCNA simultaneously in each case of astrocytoma and a positive correlation has been observed between the levels of these parameters in GBMs and in Grade III astrocytomas. The correlation between EGFR expression and PCNA labeling index in GBMs as well as in Grade III astrocytomas suggests that the tumor proliferation, at least in higher grades of astrocytomas is dependent in some measure on EGF and EGFR-related signaling pathways. Sugawa et al., ${ }^{[36]}$ compared proliferative activity of malignant glioma cells lines transfected with wild-type EGFR with that of mutant EGFR. They found that in tissue culture both have same proliferative activity. However, when the cells expressing mutant EGFR were implanted in nude mice, the tumorigenic capacity was much enhanced. They also found that the apoptotic index of tumors derived from mutant EGFR transfected cells was $<0.1 \%$, whereas that of wild-type EGFR transfected cell was $<1 \%$. These results suggest that aberrant EGFR stimulates proliferation and inhibits apoptosis. Pederson et al. ${ }^{[13]}$ and Engerbraten et al., ${ }^{[35]}$ studied that EGF increases the volume of tumor spheroids obtained from glioma cells. Mottalese et al., ${ }^{[37]}$ found that the rate of PCNA positive cells is directly associated with EGFR expression and significantly correlates with morphological grading of astrocytomas. It would be further interesting to compare the expression levels of EGFR and other proliferative markers such as Ki-67 in cases of Grade III astrocytoma and Grade IV glioblastoma as PCNA LI estimation only is associated with some degree of overestimation of proliferative potential due to its long half-life as well as in vitro induction of PCNA expression by other growth factors.

\section{Acknowledgment}

The authors are grateful to Dr Abhijit Hazra, IPGME and R, Kolkata, India and Prof. B Mukhopadhyay of the Indian Statistical Institute, Kolkata, India for their help in the statistical analysis throughout the study.

\section{References}

1. Lantos PL, VandenBerg SR, Kleihues P. Tumours of the nervous system. In: Graham DI, Lantos PL, editors. Greenfield's neuropathology. 6th ed. London: Arnold; 1996. p. 583-879.

2. Fults D, Brockmeyer D, Tullous MW, Pedone CA, Cawthon RM. p53 mutation and loss of heterozygosity on chromosomes 17 and 10 during human astrocytoma progression. Cancer Res 1992;52:674-9.

3. Henson JW, Schnitker BL, Correa KM, von Deimling A, Fassbender $\mathrm{F}, \mathrm{Xu} \mathrm{HJ}$, et al. The retinoblastoma gene is involved in malignant progression of astrocytomas. Ann Neurol 1994;36:714-21.

4. James CD, Carlbom E, Dumanski JP, Hansen M, Nordenskjold M, Collins VP, et al. Clonal genomic alterations in glioma malignancy stages. Cancer Res 1988;48:5546-51.

5. Wong AJ, Bigner SH, Bigner DD, Kinzler KW, Hamilton SR, Vogelstein B. Increased expression of the epidermal growth factor receptor gene in malignant gliomas is invariably associated with gene amplification. Proc Natl Acad Sci USA 1987;84:6899-903.

6. Ullrich A, Coussens L, Hayflick JS, Dull TJ, Gray A, Tam AW, et al. Human epidermal growth factor receptor cDNA sequence and aberrant expression of the amplified gene in A431 epidermoid carcinoma cells. Nature 1984;309:418-25.

7. Mischel PS, Shai R, Shi T, Horvath S, Lu KV, Choe G, et al. Identification of molecular subtypes of glioblastoma by gene expression profiling. Oncogene 2003;22:2361-73.

8. Nagane M, Coufal F, Lin H, Bögler O, Cavenee WK, Huang HJ. A common mutant epidermal growth factor receptor confers enhanced tumorigenicity on human glioblastoma cells by increasing proliferation and reducing apoptosis. Cancer Res 1996;56:5079-86.

9. Prigent SA, Nagane M, Lin H, Huvar I, Boss GR, Feramisco JR, et al. Enhanced tumorigenic behavior of glioblastoma cells expressing a truncated epidermal growth factor receptor is mediated through the Ras-She-Grb2 pathway. J Biol Chem 1996;271:25639-45.

10. Torp SH, Helseth E, Dalen A, Unsgaard G. Epidermal growth factor receptor expression in human gliomas. Cancer Immunol Immunother 1991;33:61-4.

11. Huncharek M, Kupelnick B. Epidermal growth factor receptor gene amplification as a prognostic marker in glioblastoma multiforme: Results of a meta-analysis. Oncol Res 2000;12:107-12.

12. Worm K, Dabbagh P, Schwechheimer K. Reverse transcriptase polymerase chain reaction as a reliable method to detect epidermal growth factor receptor exon 2-7 gene deletion in human glioblastomas. Hum Pathol 1999;30:222-7.

13. Pedersen PH, Ness GO, Engebraaten O, Bjerkvig R, Lillehaug JR, Laerum OD. Heterogeneous response to the growth factors [EGF, PDGF (bb), TGF-alpha, bFGF, IL-2] on glioma spheroid growth, migration and invasion. Int J Cancer 1994;56:255-61.

14. Wong AJ, Ruppert JM, Bigner SH, Grzeschik CH, Humphrey PA, Bigner DS, et al. Structural alterations of the epidermal growth factor receptor gene in human gliomas. Proc Natl Acad Sci USA $1992 ; 89: 2965-9$.

15. Nishikawa R, Ji XD, Harmon RC, Lazar CS, Gill GN, Cavenee WK, et al. A mutant epidermal growth factor receptor common in human glioma confers enhanced tumorigenicity. Proc Natl Acad Sci USA 1994;91:7727-31.

16. Goldman CK, Kim J, Wong WL, King V, Brock T, Gillespie GY. Epidermal growth factor stimulates vascular endothelial growth factor production by human malignant glioma cells: a model of glioblastoma multiforme pathophysiology. Mol Biol Cell 1993;4:121-33.

17. Feldkamp MM, Lala P, Lau N, Roncari L, Guha A. Expression of activated epidermal growth factor receptors, Ras-guanosine triphosphate, and mitogen-activated protein kinase in human glioblastoma multiforme specimens. Neurosurgery 1999;45:1442-53.

18. El-Obeid A, Bongeam-Rudloff E, Sörby M, Ostman A, Nistér M, Westermark B. Cell scattering and migration induced by autocrine transforming growth factor alpha in human glioma cells in vitro. Cancer Res 1997;57:5598-604.

19. Nagane M, Lin H, Cavenee WK, Huang HJ. Expression of a specific mutant epidermal growth factor receptor mediates glioma cell invasion in vivo. Proc Am Assoc Cancer Res 1996;36:519-26.

20. Nagane M, Levitzki A, Gazit A, Cavenee WK, Huang HJ. Drug resistance of human glioblastoma cells conferred by a tumor-specific mutant epidermal growth factor receptor through modulation of Bel-XL and caspase-3-like proteases. Proc Natl Acad Sci USA 1998;95:5724-9.

21. Bian XW, Shi JQ, Liu FX. Pathologic significance of proliferative activity and oncoprotein expression in astrocytic tumors. Anal Quant Cytol Histol 2000;22:429-37.

22. Han Y, Caday CG, Nanda A, Cavenee WK, Huang HJ. Tyrphostin AG 1478 preferentially inhibits human glioma cells expressing truncated rather than wild-type epidermal growth factor receptors. Cancer Res 1996;56:3859-61.

23. Och W, Mariak Z, Smółka M, Badowski J, Koziorowski M. Epidermal growth factor expression in brain neoplasms. Neurol Neurochir Pol 2000;34:1165-72.

24. Ringertz N. Grading of gliomas. Acta Pathol Microbiol Scand $1950 ; 27: 51-64$.

25. Hall PA, Coates PJ, Goodlad RA, Hart IR, lane DP. Proliferating cell nuclear antigen expression in non-cycling cells may be induced by growth factors in vivo. Br J Cancer 1994;70:244-7. 
26. Masih PJ, Kunnev D, Melendy T. Mismatch Repair proteins are recruited to replicating DNA through interaction with Proliferating Cell Nuclear Antigen (PCNA). Nucleic Acids Res 2008;36:67-75.

27. Sallinen PK, Haapasalo HK, Visakorpi T, Helén PT, Rantala IS, Isola JJ, et al. Prognostication of astrocytoma patient survival by Ki-67 (MIB-1), PCNA, and S-phase fraction using archival paraffin-embedded samples. J Pathol 1994;174:275-82.

28. Allegranza A, Girlando S, Arrigoni GL, Veronese S, Mauri FA, Gambacorta M, et al. Proliferating cell nuclear antigen expression in central nervous system neoplasms. Virchows Arch A Pathol Anat Histopathol 1991;419:417-23.

29. Scott RJ, Hall PA, Haldane JS, van Noorden S, Price Y, Lane DP, et al. A comparison of immunohistochemical markers of cell proliferation with experimentally determined growth fraction. J Pathol 1991;165:173-8.

30. van der Valk P, Lindeman J, Kamphorst W. Growth factor profiles of human gliomas: Do non-tumour cells contribute to tumour growth in glioma? Ann Oncol 1997;8:1023-9.

31. Smith JS, Tachibana I, Passe SM, Huntley BK, Borell TJ, Iturria N, et al. PTEN mutation, EGFR amplification, and outcome in patients with anaplastic astrocytoma and glioblastoma multiforme. J Natl Cancer Inst 2001;93:1246-56

32. Waha A, Baumann A, Wolf HK, Fimmers R, Neumann J, Kindermann $\mathrm{D}$, et al. Lack of prognostic relevance of alterations in the epidermal growth factor receptor-transforming growth factor-alpha pathway in human astrocytic gliomas. J Neurosurg 1996;85:634-41.

33. Bouvier-Labit C, Chinot O, Ochi C, Gambarelli D, Dufour H, FigarellaBranger D. Prognostic significance of Ki67, p53 and epidermal growth factor receptor immunostaining in human glioblastomas. Neuropathol Appl Neurobiol 1998;24:381-8.

34. Yoshimura J, Onda K, Tanaka R, Takahashi H. Clinicopathological study of diffuse type brainstem gliomas: Analysis of 40 autopsy cases. Neurol Med Chir 2003;43:375-82.

35. Engebraaten O, Bjerkvig R, Pedersen PH, Laerum OD. Effects of EGF, bFGF, NGF and PDGF (bb) on cell proliferative, migratory and invasive capacities of human brain-tumour biopsies in vitro. Int J Cancer 1993;53:209-14.

36. Sugawa N, Yamamoto K, Ueda S, Morita N, Kita M, Nishino H, et al. Function of aberrant EGFR in malignant gliomas. Brain Tumor Pathol 1998;15:53-7.

37. Mottolese M, Natali PG, Coli A, Bigotti G, Benevolo M, Cione A, et al. Comparative analysis of proliferating cell nuclear antigen and epidermal growth factor receptor expression in glial tumours: Correlation with histological grading. Anticancer Res 1998;18:1951-6.

Accepted on 18-04-2008

Source of Support: Nil, Conflict of Interest: None declared. 